Article

\title{
The Effects of Hot Water and Ultrasonication Pretreatment of Microalgae (Nannochloropsis oculata) on Biogas Production in Anaerobic Co-Digestion with Cow Manure
}

\author{
Muhammad Saleem ${ }^{1}$, Muhammad Usman Hanif ${ }^{2,3}$, Ali Bahadar ${ }^{4, *}$, Hamid Iqbal ${ }^{2,5}$ (D, \\ Sergio C. Capareda ${ }^{3}$ and Adeel Waqas ${ }^{6}$ (D) \\ 1 Department of Industrial Engineering, King Abdulaziz University, Rabigh 21911, Saudi Arabia; \\ msaleim1@kau.edu.sa \\ 2 Institute of Environmental Science and Engineering, School of Civil and Environmental Engineering, \\ National University of Sciences and Technology, Sector H-12, Islamabad 45710, Pakistan; \\ usman_hanif90@live.com (M.U.H.); hamid_nust@yahoo.com (H.I.) \\ 3 Bio-Energy Testing and Analysis Laboratory (BETA Lab), Biological and Agricultural Engineering \\ Department, Texas A \& M University, College Station, TX 77843, USA; scapareda@tamu.edu \\ 4 Department of Chemical and Materials Engineering, King Abdulaziz University, Rabigh 21911, Saudi Arabia \\ 5 Rawalpindi Waste Management Company, A-81, Iran Road, Satellite Town, Rawalpindi 46300, Pakistan \\ 6 Center for Advanced Studies in Energy, National University of Sciences and Technology, \\ Islamabad 45710, Pakistan; adeelwaqas@gmail.com \\ * Correspondence: absali@kau.edu.sa
}

Received: 4 October 2020; Accepted: 23 November 2020; Published: 27 November 2020

check for updates

\begin{abstract}
Anaerobic co-digestion provides a promising solution for converting inexpensive carbon from wastes to biogenic methane. We used microalgae (Nannochloropsis oculata) with cow manure and sludge to produce a better quantity and quality of biogas. To further improve the gas production, microalgae were pretreated with ultrasonication, hot water, and a combination of both. Interestingly, the results showed that the pretreatment of microalgae decreased biogas production by 5 to $30 \%$. The no-pretreatment runs produced a maximum of $118 \mathrm{~L}$ of biogas. The relative content of biogenic methane was higher in the pretreated feedstock (48 to 52\%) in comparison with the no-pretreatment runs (44\%). The conversion of volatile suspended solids present in the feedstock to total biogenic methane production was highest in hot-water-treated runs. The carbon content in the gas produced by the pretreated microalgae peaked (38\%) in the middle of the experiment (i.e., at 45 days), whereas for no-pretreatment runs, the content remained constant from the start to the middle and declined (from 36 to $34 \%$ ) at the end of the experiment (i.e., at 90 days). We also report the chemical structure of microalgae with and without pretreatments.
\end{abstract}

Keywords: microalgae; cotton gin trash; co-digestion; hydrocarbon; alternative energy; biogas

\section{Introduction}

Biogenic methane is a carbon-based gas primarily resulting from biological reactions by microorganisms taking place in the absence of oxygen through a process called anaerobic digestion. Anaerobic digestion takes place when (mainly) bacteria convert carbon-rich biomass to different organic products, out of which the major product is a mixture of carbon dioxide and methane, regarded as biogas. Biogas consists of almost 50 to $60 \%$ biogenic methane and 30 to $40 \%$ carbon dioxide, with few trace gases [1]. Anthropogenic carbon dioxide production through fossil fuel burning is a concern as it adds carbon to the atmosphere that was stored as fossils, whereas the carbon dioxide released from 
burning biogenic methane is considered to be carbon or climatic neutral, as it is sourced from plants that already exist in our environment [2]. Biogenic methane can be purified from the other contents of biogas and used as an alternative fuel [3].

The process of production of biogenic methane through anaerobic digestion also serves the purpose of stabilizing non-volatile carbons. The byproduct of anaerobic digestion is a non-reactive slurry or sludge that is sufficiently stabilized to be used directly as a soil amendment without harming plants or the environment.

For the production of biogenic methane, usually, the leftovers or wastes of agriculture are used, as they are readily available, the cheapest source of carbon, and require disposal that can harm the environment. During the last two decades, different organic substrates have been studied, showing the synergic effect of combined treatment [4-6]. These co-substrates commonly include cotton wastes [7], organic solid waste [6], rice stalks [8], and microalgae [9]. Due to the lesser content of biogenic methane or poor quality of resulting biogas, many researchers have attempted to mix various feedstocks [4]. This mixing of different feedstocks has not only increased the quantity of biogas but also improved the quality by increasing the relative amount of biogenic methane.

When mixing the feedstocks, various factors are considered. These factors generally include the composition of each feedstock to facilitate microorganisms' decomposition ability. The mixes contain a better carbon-to-nitrogen ratio and moisture content than a single feedstock [10]. Usually, a carbon source like agriculture waste is used with nitrogen-rich cow manure to maintain that ratio. To trigger the decomposition process, a bacteria-rich inoculum is added, which can be sludge. In this study, we used microalgae, cow manure, and sludge as a carbon source, nitrogen source, and inoculum, respectively. Microalgae are unicellular photosynthetic micro-organisms, living in saline or freshwater environments, that convert sunlight, water and carbon dioxide to algal biomass. The reason for using microalgae is that many scientists have reported an improved quantity of produced biogas as they contain abundant carbon with better nitrogen content than any other agriculture waste [11]. During the co-digestion, microalgae not only help in maintaining the moisture content of the feedstock mixture, they also keep the $\mathrm{pH}$ of the mixture high, i.e., rendering it alkaline and providing better micro-nutrients than any other co-substrate [12]. Algal growth is remarkably higher and more efficient than that of other energy crops as it can be managed even in harsh environments without any time restrictions. These can also be grown in salt water and wastewater systems, and demonstrate high carbon dioxide reductions [13].

In a recent study [14], a thermal-ultrasonication pretreatment of manure helped increase the production of biogenic methane by $41 \%$. This is because physical pretreatments trigger cell lysis and overcome the hindrances of lignin and cellulose [15]. The pretreatment of feedstock helps in improving hydrolysis and methanogenesis during the digestion process, resulting in an increase of biodegradability and enhancement of biogas production [16]. In comparison with chemical treatments, physical treatments are effective and have fewer waste management issues. In our experiments, we used physical pretreatments—hot water and ultrasonication—of microalgae. As suggested by [17], a combination of these pretreatments was applied to microalgae before making mixtures.

We hypothesized that as microalgae have been proved to be a better feedstock for high biogas production, microalgae pretreated with hot water and ultrasonication would further improve the quantity and quality of biogas. This study will help in understanding the chemical changes in the feedstock and products due to pretreatments.

\section{Materials and Methods}

\subsection{Preparation of Digester Mixtures}

Three different components were used to prepare the digestate mixtures: cow manure, microalgae, and sludge (inoculum). Fresh cow manure was obtained from the Animal Science Teaching, Research, and Education Center ASTREC facility at Texas A\&M University. Fresh inoculum was obtained from 
the recycling stream of the anaerobic digester in the Texas A\&M and was used the same day for an experiment.

\subsection{Pretreatment of Microalgae}

In this study, microalgae were pretreated with three types of pretreatments (ultrasonication, hot water, and their combination). An ultrasonicator made by Hielscher Ultrasonic Processors, Ringwood, NJ, USA was used to perform the ultrasonication process on a solution of $10 \%$ microalgae biomass solids. An autoclave set at $121^{\circ} \mathrm{C}, 15$ psi was used to perform the hot water pretreatment on a solution of $10 \%$ solids for $1 \mathrm{~h}$ using Borex Bottles. The combination set included both types of pretreatment methods.

\subsection{Experimental Setup}

A lab-scale digester setup was used for carrying out this experiment, as shown in Figure 1. The digesters were placed in an environmentally stable room at temperature $35 \pm 2{ }^{\circ} \mathrm{C}$. The digesters were constructed from clear PVC material with threading support on each end. The ends were fixed with caps; these caps were drilled to fit threaded valves. The bottom cap had one valve while the top one was provided with two valves, i.e., a valve and a gas collection nozzle. The caps were fixed using plumber's tape or putty to avoid all leakages, and the digesters were filled with the proportions/types of biomass detailed in Table 1.
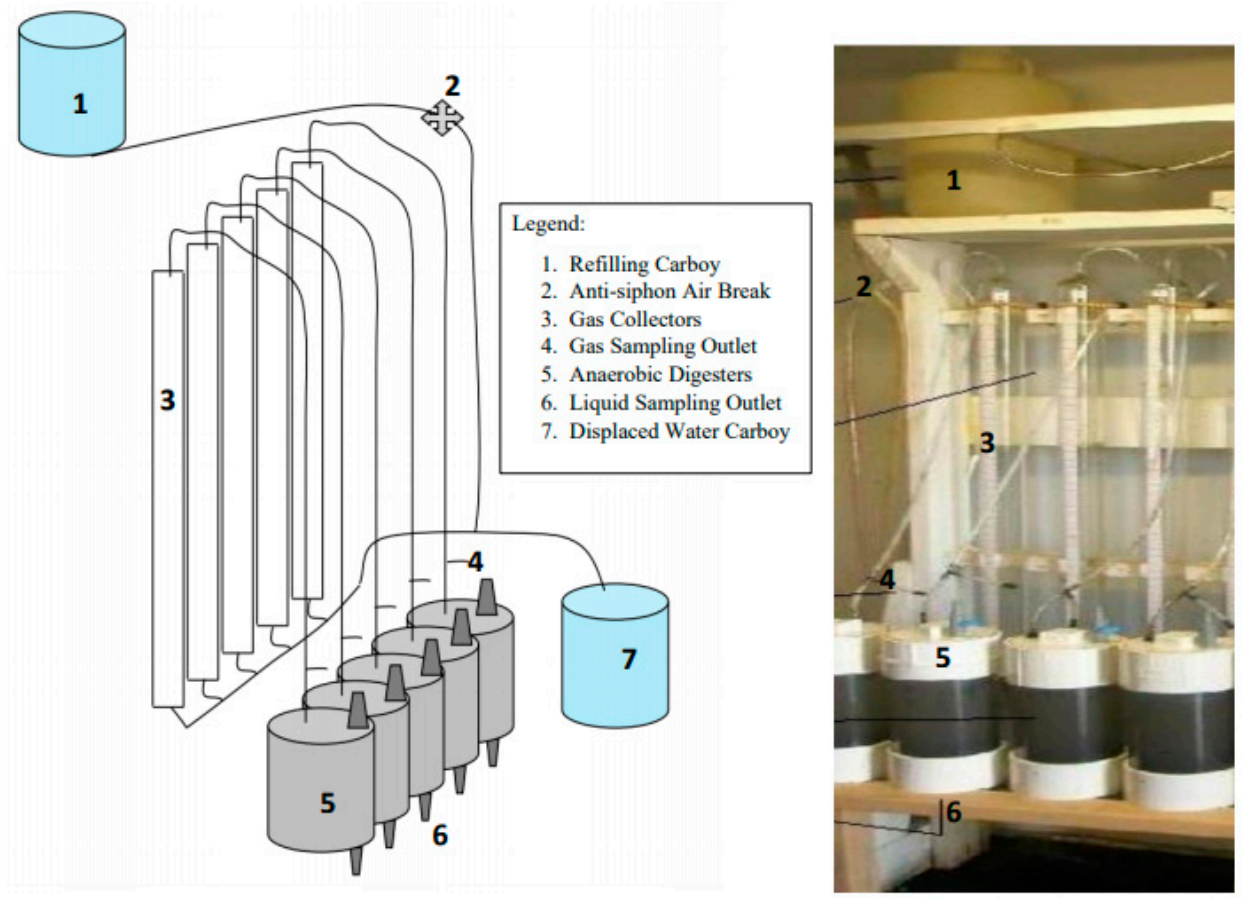

Figure 1. Experimental setup for the anaerobic digestion of biomass.

The digesters were interconnected with the gas collectors by rubber tubing. The mainline was connected to filling and displacement carboys with a T-junction with a break to prevent siphoning. The filling and displacement carboys were placed high and low, respectively, to help the filling and displacement. The gas collectors were re-filled from the top carboy while the displaced water, as a result of gas production, filled the displacement carboy placed at the bottom.

The experimental setup used for this experiment was classified based on the treatment method. Each mixture contained one kilogram of animal manure and one liter of inoculum sludge. The non-control mixtures included either pretreated or non-pretreated microalgae $(550 \mathrm{~mL})$. 
Table 1. Treatments used for the experiment.

\begin{tabular}{cccc}
\hline Pretreatments & Microalgae $(\mathbf{m L})$ & Cow Manure (grams) & Sludge $(\mathbf{m L})$ \\
\hline Hot Water $(\mathrm{HW})$ & 550 & 1000 & 1000 \\
Ultrasonication $(\mathrm{U})$ & 550 & 1000 & 1000 \\
HW + U & 550 & 1000 & 1000 \\
No Pretreatment & 550 & 1000 & 1000 \\
Cow Manure + Sludge & - & 1000 & 1000 \\
Sludge & - & - & 1000 \\
\hline
\end{tabular}

Note that $\mathrm{pH}$ was kept at 7.2 for each treatment.

The generated gas volumes were measured on a daily basis according to the amount of water displaced in each of the gas collectors. To guarantee uniform moisture content and maximum contact between substrates and microorganisms, the reactors were inverted and reverted once a day. Potential leakage in the tubes was checked occasionally by disconnecting all tubes and fittings and testing for blockages and leakages. During the process, no leakages were detected. After attaining the readings, the gas collectors were refilled with water, and the process was repeated. The $\mathrm{pH}$ of the digesters was monitored on a weekly basis by taking a slurry sample from the bottom valve of each of the digesters. If the $\mathrm{pH}$ of the digesters caused inhibition in gas production, the digester was normalized with $5 \mathrm{M}$ $\mathrm{NaOH}$ solution.

\subsection{Analytical Methods for Pretreatment Effects}

The effects of pretreatment on the structural composition of microalgae were determined using the analytical protocols developed at the National Renewable Energy Laboratory (NREL) of the US Department of Energy. These protocols determine three aspects, as studied by [18]; these are (i) total solids in biomass and total dissolved solids in liquid process samples, (ii) extractives in biomass, and (iii) structural carbohydrates and amounts of lignin in biomass.

The structural properties were evaluated by the use of a Fourier transform infrared (FTIR) spectroscope developed by Shimadzu, an IR Affinity- 1 with a MIRacle universal sampling accessory, in the microalgae before and after pretreatments. Biomass particles were dried at $105^{\circ} \mathrm{C}$ for $24 \mathrm{~h}$ and ground before analysis. The range of 4000 to $700 \mathrm{~cm}^{-1}$ with a resolution of $4 \mathrm{~cm}^{-1}$ was used to collect the infrared spectra. The determined structural properties of these compounds with IR wavenumbers are presented in Table 2.

Table 2. Functional groups and their respective wavelengths on FTIR spectra.

\begin{tabular}{cc}
\hline Functional Group & Wavenumber $\left(\mathbf{c m}^{-\mathbf{1}}\right)$ \\
\hline C=O, ester carboxyl & $1240-1732$ \\
C-O-C, anti-symmetric stretch & $1170-1150$ \\
B-D, cellulose & 898 \\
OH region, phenolic & 1370 \\
CH stretch, aliphatic & 1370 \\
C-H, deformation & 1595 \\
\hline
\end{tabular}

Three biomasses were also studied for proximate and ultimate analysis. In the proximate analysis, moisture content (MC) was determined using ASTM E871-72, volatile combustible matter (VCM) was determined using ASTM E 872-82, and the fixed carbon (FC) and ash content of the biomass was determined using ASTM D 1102-84. The heating value of the biomass was also tested using a PARR isoperibol bomb calorimeter, available in Beta Lab, A\&M Texas. Ultimate analysis of the biomass was carried out using a Vario MICRO Elemental Analyzer, where carbon (C) and hydrogen (H) were analyzed in accordance with ASTM E 777, sulfur (S) content was measured using ASTM E 775, and nitrogen $(\mathrm{N})$ was measured using ASTM E 778. The oxygen content of the biomass was determined as the difference between $100 \%$ and the sum of $\mathrm{C}, \mathrm{H}, \mathrm{N}, \mathrm{S}$, and Ash. 


\subsection{Gas Analysis}

The gas samples for analysis were taken when gas collectors were emptied. This sampling was usually done when the gas collectors were refilled, i.e., every second day. The samples obtained from the gas collectors were further analyzed using an SRI Gas Chromatograph for its composition. The SRI Multiple Gas Analyzer 1 (MG 1) gas chromatograph (GC) was equipped with an on-column injection system and two detectors: a helium ionization detector (HID) and a thermal conductivity detector (TCD). The SRI analyzed the contents of methane, carbon dioxide, and other gases in the biogas mixtures.

\section{Results}

\subsection{Characterization of Three Biomasses}

The composition of the feedstock is shown in Table 3. Of the components of cow manure and microalgae, carbon was present in the maximum quantity, with sulfur as the minimum. The microalgae and sludge (inoculum) showed high nitrogen content as compared to the other feedstocks. This resulted in lower carbon-to-nitrogen ratios of the microalgae and sludge. The microalgae showed high nitrogen levels as they contain proteins found in algal cells. The volatile suspended solids were found to be higher in cow manure. The volatiles were lowest in sludge, which showed the spent microbial activity from the wastewater treatment process. The microalgae provided high amounts of nutrients and volatile solids, proving to be a viable anaerobic digestion resource.

Table 3. Composition of feedstock for anaerobic digestion.

\begin{tabular}{cccc}
\hline Composition $(\%$ Except C/N) & Cow Manure & Microalgae & Sludge \\
\hline Bulk density $\left(\mathrm{kg} / \mathrm{m}^{3}\right)$ & 998 & 695 & 415 \\
Carbon & 36.13 & 38.86 & 25.89 \\
Nitrogen & 2.3 & 7.66 & 5.97 \\
Hydrogen & 4.67 & 5.44 & 3.83 \\
Sulfur & 0.11 & 0.69 & 0.45 \\
C/N & 16.01 & 5.07 & 6.52 \\
VSS (\% of TS) & 71.5 & 39.67 & 24.93 \\
\hline VSS = volatile suspended solids, TS = Total Solids.
\end{tabular}

Figure 2 shows the FTIR spectra of microalgae before feeding into the digester. The figure compares the structural changes in microalgae with different pretreatments. The overall structure of microalgae itself and pretreated microalgae remained almost the same, but the relative abundance of organic species changed with changing pretreatments. Hot-water-pretreated microalgae show a well-defined peak, whereas other pretreated samples' spectra are comparatively smooth. The relative abundance of organics increased with microalgae pretreatments. The order of high to low peaks can be observed as hot water $>$ ultrasonication $>$ hot water + ultrasonication $>$ no pretreatment.

The peaks shown in hot-water-treated microalgae are sharp, representing a uniform distribution of each component. This represents strong absorption peaks with less overlapping due to minerals like calcium carbonate at $1463 \mathrm{~cm}^{-1}$. This suggests that the pretreatments significantly affected the overall structure of the biomass, but the relative abundance of the species remained almost unchanged.

Cellulose, lignin, carboxylic acids, alkynes, alcohols, and phenols were significantly increased in the pretreated microalgae. The relative abundance of alkynes was significantly increased in hot-water-treated microalgae compared to the other pretreatments. The aromatics were higher in ultrasonicated pretreatments than hot-water-treated microalgae. This suggests that hot water did not influence the relative amounts of aromatics, and ultrasonication did not affect alkynes. 


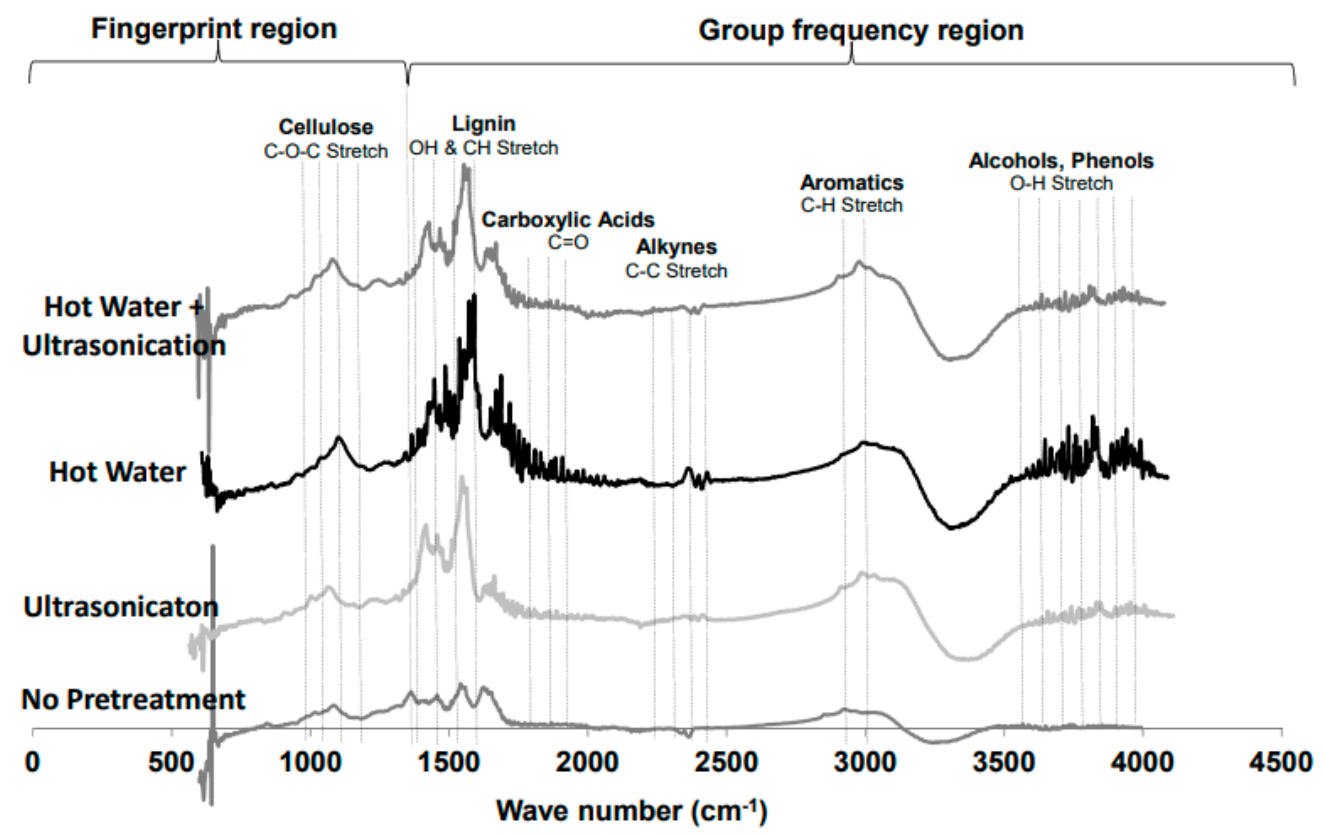

Figure 2. FTIR spectra of biogas produced from the digestion of microalgae.

\subsubsection{Biogas Production}

Biogas production from the digestion of biomass requires a period of initiation, where the microbes acclimatize for further degradation of biomass mixtures. This period may vary with the amount of inoculum introduced and the type of feedstock. A factor that can play a major role in reducing the acclimatization time is pretreatment. Among the pretreatments of feedstock, ultrasonication and hot water treatment are accepted methods. Figure 3 shows the biogas production during a digestion period of 90 days with different pretreatments. The figure shows that the control had the minimum acclimatizing period of 26 days, with the maximum period observed for the hot water + ultrasonication pretreatment feedstock. In this phase, hydrolysis occurs, which results in the production of monosaccharides and acids [19]. The beginning of methanogenesis and an exponential increase in biogas production can be observed in Figure 3. The figure suggests that the pretreatment did not increase the total biogas production by microalgae but decreased the amount of biogas. This case is opposite to that in a previously reported study [14], where they used thermal sonication as a pretreatment of goose manure. This can be attributed to the type and nature of the feedstock; for instance, manures are comparatively stable relative to raw organic matter, which in our case would be the microalgae. Pretreatments may not increase the biogas quantity every time. A recent study [20] criticized the use of high-intensity pretreatments as they do not always increase biogenic methane production. Pretreatments have the potential to increase the soluble content of the substrate, resulting in biogenic methane production. It is clear from the figure that the combined pretreatments showed a delayed increase in biogas production and an ultimately lower cumulative amount in the given time period. This may be due to a change in the physical properties of the biomass (like hydrophobicity), creating a temporary dormancy due to pretreatment. Further studies on change in the hydrophobic or hydrophilic nature of feedstock due to pretreatment could clarify this phenomenon. Among the pretreatments, ultrasonication alone produced better results in terms of biogas production. Hot water, on the other hand, reduced the degradation process and hence decreased the amount of biogas produced. 


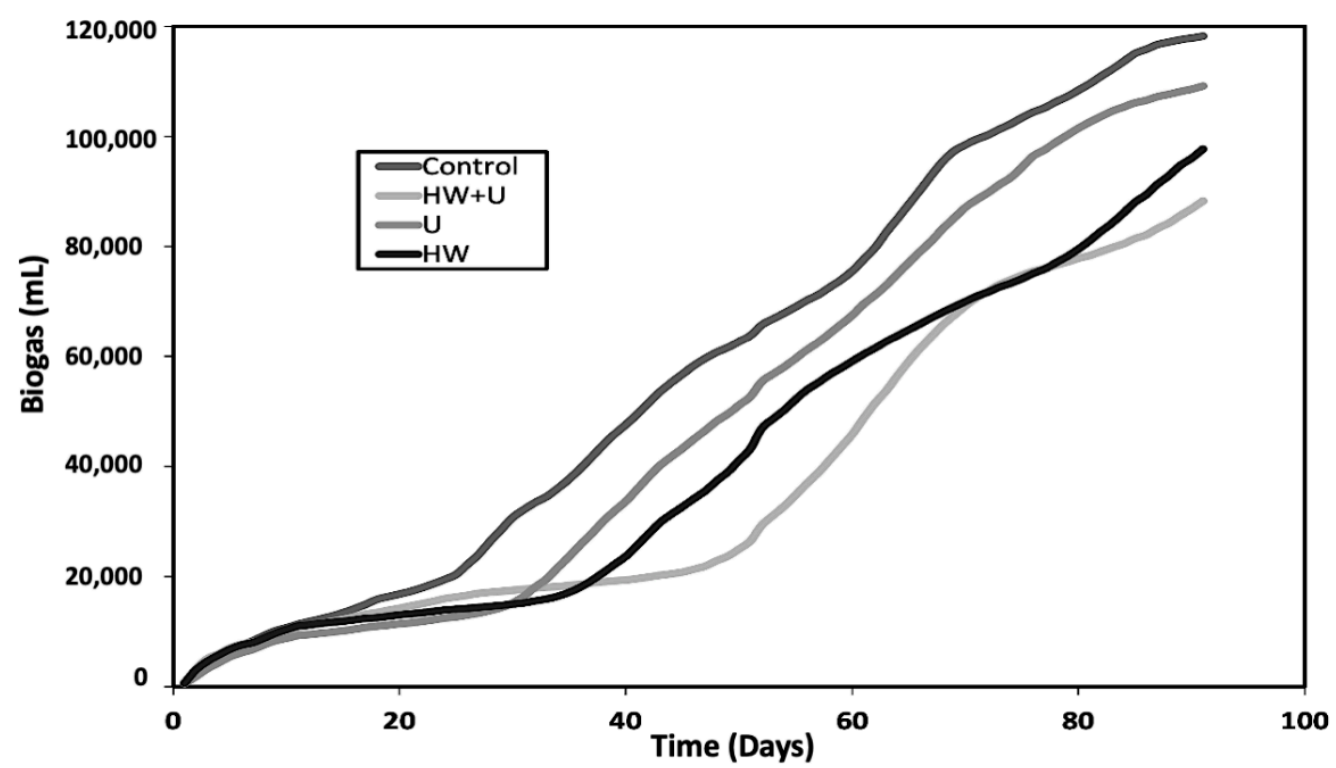

Figure 3. Biogas yield from the digestion of microalgae with different pretreatments.

\subsubsection{Substrate Composition during the Digestion Process}

The ultimate analysis results of the substrate left at the beginning ( 0 days), middle (45 days), and end (90 days) of the digestion process are shown in Figure 4. The figure shows that a major proportion of substrate consisted of carbon (33 to 38\%). The minimum change in the amount of sulfur $(<1 \%)$ implies a better quality of biogas, as sulfur may form $\mathrm{H}_{2} \mathrm{~S}$ gas, which can contaminate methane. Initially, the carbon content was found to be greatest for the ultrasonicated feedstock, but it was reduced with elapsing time. The carbon content remained consistent for the rest of the treatment until the middle (45 days) of the digestion period and was reduced at the finalization stage (Figure 4). Assuming that the remaining component is oxygen, oxygen was the main constituent at almost $60 \%$ of the elemental composition. The relative increase in carbon content gives information on the degradation process. As carbon-to-nitrogen $(\mathrm{C} / \mathrm{N})$ ratios primarily govern the rate of degradation, the microbial degradation factors can be ascertained from the figure. An increase of the $\mathrm{C} / \mathrm{N}$ ratio reduces the negative effects of ammonia and results in maximum methane potential. Ammonia accumulation creates instability in the process, resulting in low gas production [21].

Table 4 shows the production rates of both phases. The highest amount of biogas was produced by microalgae without any pretreatment. On average, microalgae ( $420 \mathrm{~L}$ of total biogas) performed well in the production of biogas. Table 4 shows that the methane produced per gram of volatile suspended solids was greatest for microalgae pretreated with hot water. The hot water treatment improved the enzymatic digestibility of the biomass by removing hemicellulose and improving the accessibility of cellulase enzyme to cellulose [22]. The overall biogas production efficiency was not affected by the microalgae pretreatments, but methane production efficiency was significantly affected by the pretreatments. 


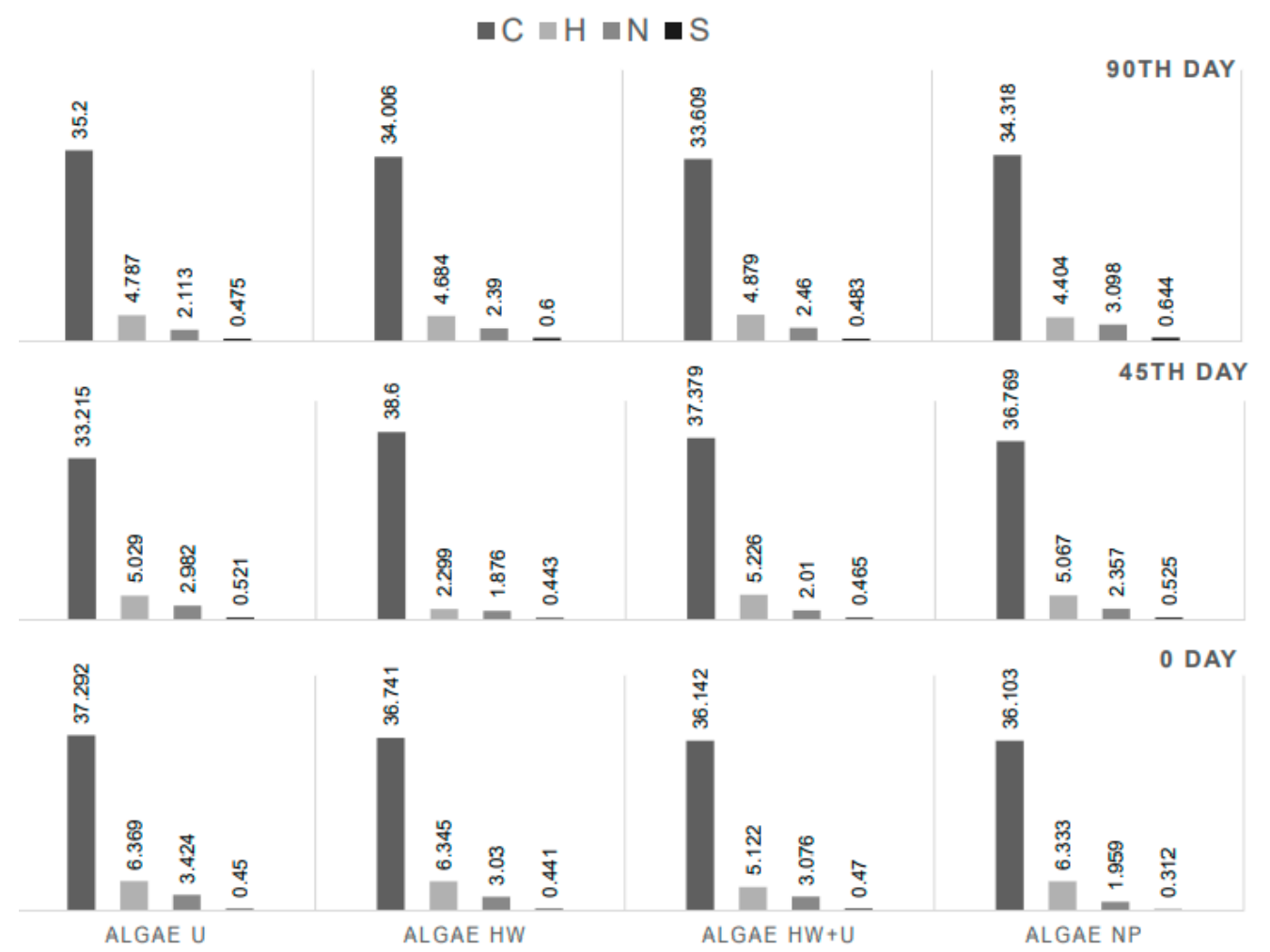

Figure 4. Ultimate analysis of the substrate during the digestion process of microalgae.

Table 4. Production of methane by microalgae with different pretreatments.

\begin{tabular}{|c|c|c|c|c|c|}
\hline Pretreatments & VSS $_{\text {consumed }}(\mathrm{g})$ & Biogas $_{\text {produced }}(\mathrm{L})$ & $\begin{array}{l}\text { Average } \mathrm{CH}_{4} \\
\text { (\% of Biogas) }\end{array}$ & $\mathrm{CH}_{4}$ Produced (L) & $\begin{array}{c}\mathrm{CH}_{4} \text { Produced } \\
\text { (L/g of VSS) }\end{array}$ \\
\hline $\mathrm{HW}+\mathrm{U}$ & 135.40 & 88.29 & 53.54 & 47.27 & 0.35 \\
\hline HW & 124.50 & 97.73 & 52.17 & 50.98 & 0.41 \\
\hline $\mathrm{U}$ & 151.40 & 109.15 & 48.65 & 53.10 & 0.35 \\
\hline NP & 175.40 & 118.20 & 44.87 & 53.04 & 0.30 \\
\hline
\end{tabular}

$\mathrm{HW}=$ hot water, $\mathrm{U}=$ ultrasonication, and $\mathrm{NP}=$ no pretreatment.

\section{Conclusions}

Physical pretreatment of co-biomass was applied to produce better-quality biogas. The production of biogas decreased by 5 to $30 \%$ when pretreatments were applied to microalgae. The relative content of biogenic methane was higher for the pretreated feedstock (48 to 52\%) than for the no-pretreatment runs $(44 \%)$. The conversion rate of volatile suspended solids present in the feedstock to total biogenic methane production was highest in hot-water-treated runs. The carbon content in the gas produced by the pretreated microalgae peaked (38\%) in the middle of the experiment (i.e., at 45 days), whereas for no-pretreatment runs, the content remained consistent from the start to the middle and then declined (from 36 to $34 \%$ ) at the end of the experiment (i.e., at 90 days). We also reported the chemical structure of microalgae with and without pretreatments.

Author Contributions: Conceptualization, S.C.C., M.S. and M.U.H.; data curation, M.S. and H.I.; investigation, M.U.H., A.B. and A.W.; methodology, S.C.C.; supervision, S.C.C.; validation, A.B., M.S., and A.W.; visualization, M.S., A.B., and H.I.; writing-original draft, M.S., M.U.H., S.C.C., H.I., A.B., and A.W.; writing-review and editing, M.U.H., M.S., S.C.C., H.I., A.B., and A.W. All authors have read and agreed to the published version of the manuscript.

Funding: This article was funded by the Deanship of Scientific Research (DSR) at King Abdulaziz University, Jeddah. The author therefore acknowledges DSR with thanks for technical and financial support. 
Acknowledgments: The authors are grateful to the Higher Education Commission (HEC) of Pakistan, Bio-Energy Testing and Analysis Laboratory (BETA Lab), Biological and Agricultural Engineering Department, Texas A\&M University, and National University of Sciences and Technology for supporting this study.

Conflicts of Interest: The authors declare no conflict of interest.

\section{References}

1. Bumbiere, K.; Gancone, A.; Pubule, J.; Kirsanovs, V.; Vasarevicius, S.; Blumberga, D. Ranking of Bioresources for Biogas Production. Environ. Clim. Technol. 2020, 24, 368-377. [CrossRef]

2. Durdevic, D.; Hulenic, I. Anaerobic Digestate Treatment Selection Model for Biogas Plant Costs and Emissions Reduction. Processes 2020, 8, 142. [CrossRef]

3. Ward, A.J.; Hobbs, P.J.; Holliman, P.J.; Jones, D.L. Optimisation of the anaerobic digestion of agricultural resources. Bioresour. Technol. 2008, 99, 7928-7940. [CrossRef] [PubMed]

4. Esposito, G.; Frunzo, L.; Liotta, F.; Panico, A.; Pirozzi, F. Bio-methane potential tests to measure the biogas production from the digestion and co-digestion of complex organic substrates. Open Environ. Eng. J. 2012, 5, 1-8. [CrossRef]

5. Macias-Corral, M.; Samani, Z.; Adrian, H.; Smith, G.; Funk, P.; Yu, H.; Longworth, J. Anaerobic digestion of municipal solid waste and agricultural waste and the effect of co-digestion with dairy cow manure. Bioresour. Technol. 2008, 99, 8288-8293. [CrossRef] [PubMed]

6. Esposito, G.; Frunzo, L.; Panico, A.; Pirozzi, F. Modelling the effect of the OLR and OFMSW particle size on the performances of an anaerobic co-digestion reactor. Process Biochem. 2011, 46, 557-565. [CrossRef]

7. Adl, M.; Sheng, K.; Gharibi, A. Technical assessment of bioenergy recovery from cotton stalks through anaerobic digestion process and the effects of inexpensive pre-treatments. Appl. Energy 2012, 93, 251-260. [CrossRef]

8. Iyagba, E.T.; Mangibo, I.A.; Mohammad, Y.S. The study of cow dung as co-substrate with rice husk in biogas production. Sci. Res. Essay 2009, 4, 861-866.

9. Perazzoli, S.; Bruchez, B.M.; Michelon, W.; Steinmetz, R.L.R.; Mezzari, M.P.; Nunes, E.O.; da Silva, M.L.B. Optimizing biomethane production from anaerobic degradation of Scenedesmus spp. biomass harvested from algae-based swine digestate treatment. Int. Biodeterior. Biodegrad. 2016, 109, 23-28. [CrossRef]

10. Yang, Q.; Wu, B.; Yao, F.; He, L.; Chen, F.; Ma, Y.; Shu, X.; Hou, K.; Wang, D.; Li, X. Biogas production from anaerobic co-digestion of waste activated sludge: Co-substrates and influencing parameters. Rev. Environ. Sci. Bio/Technol. 2019, 18, 771-793. [CrossRef]

11. Solé-Bundó, M.; Garfí, M.; Ferrer, I. Pretreatment and co-digestion of microalgae, sludge and fat oil and grease (FOG) from microalgae-based wastewater treatment plants. Bioresour. Technol. 2020, 298, 122563.

12. Solé-Bundo, M.; Passos, F.; Romero-Guiza, M.S.; Ferrer, I.; Astals, S. Co-digestion strategies to enhance microalgae anaerobic digestion: A review. Renew. Sustain. Energy Rev. 2019, 112, 471-482. [CrossRef]

13. Schenk, P.M.; Thomas-Hall, S.R.; Stephens, E.; Marx, U.C.; Mussgnug, J.H.; Posten, C.; Kruse, O.; Hankamer, B. Second Generation Biofuels: High-Efficiency Microalgae for Biodiesel Production. Bioenergy Res. 2008, 1, 20-43. [CrossRef]

14. Hassan, M.; Zhao, C.; Ding, W. Enhanced methane generation and biodegradation efficiencies of goose manure by thermal-sonication pretreatment and organic loading management in CSTR. Energy 2020, 198, 117370. [CrossRef]

15. Tiehm, A.; Nickel, K.; Zellhorn, M.; Neis, U. Ultrasonic Waste Activated Sludge Disintegration for Improving Anaerobic Stabilization. Water Res. 2001, 35, 2003-2009. [CrossRef]

16. Karouach, F.; Bakraoui, M.; El Gnaoui, Y.; Lahboubi, N.; El Bari, H. Effect of combined mechanical-ultra-sonic pretreatment on mesophilic anaerobic digestion of household organic waste fraction in Morocco. Energy Rep. 2020, 6, 310-314. [CrossRef]

17. Magomnang, A.; Capareda, S. Improvement of Biogas Production by Sequential Pretreatment of Rice Straw and Coconut Shell for Power Generation Applications. IOP Conf. Ser. Mater. Sci. Eng. 2020, 742, 012014. [CrossRef]

18. Sluiter, A.; Hames, B.; Ruiz, R.; Scarlata, C.; Sluiter, J.; Templeton, D. Determination of Structural Carbohydrates and Lignin in Biomass; Technical Report No. NREL/TP-510-42618; National Renewable Energy Laboratory: Golden, CO, USA, 2012. 
19. Anukam, A.; Mohammadi, A.; Naqvi, M.; Granstrom, K. A Review of the Chemistry of Anaerobic Digestion: Methods of Accelerating and Optimizing Process Efficiency. Processes 2019, 7, 504. [CrossRef]

20. Sposob, M.; Kim, D.-H.; Yun, G.-S.; Yun, Y.-M. Assessment of the relationship between solubilization and biogas production on anaerobic digestion of pretreated lipid-extracted microalgae waste. Biomass Bioenergy 2020, 141, 105702. [CrossRef]

21. Kovacs, E.; Wirth, R.; Maroti, G.; Bagi, Z.; Rakhely, G.; Kovács, K.L. Biogas production from protein-rich biomass: Fed-batch anaerobic fermentation of casein and of pig blood and associated changes in microbial community composition. PLoS ONE 2013, 8, e77265. [CrossRef] [PubMed]

22. Kim, Y.; Hendrickson, R.; Mosier, N.S.; Ladisch, M.R. Liquid Hot Water Pretreatment of Cellulosic Biomass. In Biofuels; Methods in Molecular Biology (Methods and Protocols); Mielenz, J., Ed.; Humana Press: Totowa, NJ, USA, 2009; Volume 581, pp. 93-102.

Publisher's Note: MDPI stays neutral with regard to jurisdictional claims in published maps and institutional affiliations.

(C) 2020 by the authors. Licensee MDPI, Basel, Switzerland. This article is an open access article distributed under the terms and conditions of the Creative Commons Attribution (CC BY) license (http://creativecommons.org/licenses/by/4.0/). 